\title{
Prevalence and risk factors of Helicobacter pylori infection among children in Kuichong Subdistrict of Shenzhen City, China
}

\author{
Jingjing Hu ${ }^{\text {Equal first author, } 1}$, Xiangyu Wang ${ }^{\text {Equal first author, } 1,2}$, Eng Guan Chua ${ }^{3}$, Yongsheng He ${ }^{2}$, Qing Shu ${ }^{1}$, Li Zeng ${ }^{1}$, \\ Shiyang Luo ${ }^{2}$, Barry J. Marshall ${ }^{2,3}$, Aijun Liu ${ }^{\text {Corresp., } 2}$, Chin Yen Tay ${ }^{\text {Corresp. 2, } 3}$ \\ ${ }^{1}$ The First Affiliated Hospital of Shenzhen University, Shenzhen Second People's Hospital, Shenzhen, China \\ 2 Shenzhen Kuichong People's Hospital, Shenzhen, China \\ 3 The Marshall Centre for Infectious Diseases Research and Training, University of Western Australia, Perth, Western Australia, Australia \\ Corresponding Authors: Aijun Liu, Chin Yen Tay \\ Email address: liuaijunsz@163.com, alfred.tay@uwa.edu.au
}

Background: Helicobacter pylori infection is a significant burden to the public health in China as it can lead to various gastric diseases including peptic ulcers and gastric cancer. Since most infections occurred during childhood, it is therefore necessary to understand the prevalence and risk determinants of this bacterial infection in children. Herewith we conducted a cross-sectional study in the Kuichong Subdistrict of Shenzhen City to assess the prevalence and risk factors of $H$. pylori infection among children.

Methods: From September 2018 to October 2018, 1355 children aged 6-12 years from four primary schools in the Kuichong Subdistrict of Shenzhen City were recruited. These children were screened for $\mathrm{H}$. pylori infection using the ${ }^{13} \mathrm{C}$-urea breath test. In addition, parents were requested to fill out a standardized questionnaire. Chi-square test and multivariable logistic regression analysis were used to identify risk factors for $H$. pylori.

Results: Among 1355 children recruited in this study, 226 ( $16.7 \%$; $95 \% \mathrm{Cl}: 14.7 \%-18.7 \%$ ) were positive of $H$. pylori infection. Multivariable logistic regression analysis identified six factors significantly associated with $H$. pylori infection children including parent(s) with tertiary education level (OR: 0.64; $95 \% \mathrm{Cl}: 0.46-0.89$ ), testing bottle feed temperature using the mouth (OR: $1.79 ; 95 \% \mathrm{Cl}: 1.19-2.68$ ), sharing of cutlery between the feeding person and young children during meals (OR: $1.84 ; 95 \% \mathrm{Cl}$ :

1.22-2.78), eating fruit after peeling (OR: 2.56; 95\% Cl: 1.4-4.71), frequent dining out (OR: $3.13 ; 95 \% \mathrm{Cl}$ : 1.46-6.68) and snacking (OR: 1.43; $95 \% \mathrm{Cl}: 1.01-2.01$ ).

Conclusions: Overall, better educated parent(s) played a protective role against the acquisition of $H$. pylori infection in children. Testing bottle feed temperature using the mouth, cutlery sharing between the feeding person and young children, and snacking posed a lower but significant risk for $\mathrm{H}$. pylori infection. Only eating peeled fruits and frequent dining out were associated with greater infection risks. 
1 Prevalence and risk factors of Helicobacter pylori infection among children in Kuichong

2 Subdistrict of Shenzhen City, China

3 Jingjing $\mathrm{Hu}^{1 *}$, Xiangyu Wang ${ }^{1,2 *}$; Eng Guan $\mathrm{Chua}^{3}$, Yongsheng $\mathrm{He}^{2}$, Qing Shu ${ }^{1}$, Li Zeng1,

4 Shiyang Luo², Barry J. Marshall ${ }^{2,3}$, Aijun Liu' ${ }^{29}$, Chin Yen Tay ${ }^{2,3 \uparrow}$

$5{ }^{1}$ The First Affiliated Hospital of Shenzhen University, Shenzhen Second People's Hospital,

6 Shenzhen 518000, China.

$7 \quad{ }^{2}$ Shenzhen Kuichong People's Hospital, Shenzhen 518119, China.

$8{ }^{3}$ The Marshall Centre for Infectious Diseases Research and Training, University of Western

9 Australia, Perth 6009, Western Australia, Australia.

$11 *$ These authors contributed equally as co-first authors.

13 TCorresponding authors:

Dr. Aijun Liu². Email: 1164736107@qq.com

Dr. Chin Yen Tay2,3. Email: alfred.tay@uwa.edu.au 
16 Abstract

17

Background: Helicobacter pylori infection is a significant burden to the public health in China as it can lead to various gastric diseases including peptic ulcers and gastric cancer. Since most infections occurred during childhood, it is therefore necessary to understand the prevalence and risk determinants of this bacterial infection in children. Herewith we conducted a cross-sectional study in the Kuichong Subdistrict of Shenzhen City to assess the prevalence and risk factors of H. pylori infection among children.

Methods: From September 2018 to October 2018, 1355 children aged 6-12 years from four primary schools in the Kuichong Subdistrict of Shenzhen City were recruited. These children were screened for $H$. pylori infection using the ${ }^{13} \mathrm{C}$-urea breath test. In addition, parents were requested to fill out a standardized questionnaire. Chi-square test and multivariable logistic regression analysis were used to identify risk factors for $\mathrm{H}$. pylori.

Results: Among 1355 children recruited in this study, 226 (16.7\%; 95\% CI: 14.7\%-18.7\%) were positive of $H$. pylori infection. Multivariable logistic regression analysis identified six factors significantly associated with $H$. pylori infection children including parent(s) with tertiary education level (OR: 0.64; 95\% CI: 0.46-0.89), testing bottle feed temperature using the mouth (OR: 1.79; 95\% CI: 1.19-2.68), sharing of cutlery between the feeding person and young children during meals (OR: 1.84; 95\% CI: 1.22-2.78), eating fruit after peeling (OR: 2.56; 95\% 
36 CI: 1.4-4.71), frequent dining out (OR: 3.13; 95\% CI: 1.46-6.68) and snacking (OR: 1.43; 95\%

37 CI: 1.01-2.01).

38

39 Conclusions: Overall, better educated parent(s) played a protective role against the acquisition

40 of $H$. pylori infection in children. Testing bottle feed temperature using the mouth, cutlery

41 sharing between the feeding person and young children, and snacking posed a lower but

42 significant risk for $H$. pylori infection. Only eating peeled fruits and frequent dining out were

43 associated with greater infection risks. 


\section{Introduction}

45 Helicobacter pylori is a key gastric pathogen infecting nearly half of the world's population,

46 causing several gastric disorders including chronic gastritis, gastric atrophy, peptic and duodenal

47 ulcerations, gastric mucosa-associated lymphoid tissue (MALT) lymphoma and gastric adenocarcinoma (Marshall \& Windsor 2005). In China, in tandem with a high overall H. pylori prevalence rate of $55.8 \%$, gastric cancer has been reported as the third most predominant cancer type and the second leading cause of cancer-related death in this nation, with an estimated 456,124 new cases and 390,182 deaths in 2018, respectively (Feng et al. 2019; Hooi et al. 2017).

Based on a recent systematic review analyzing the medical expenses of Chinese patients with gastric cancer during 2002-2011, it was estimated that in 2012 the first course treatments alone would cost China nearly $\$ 3$ billion USD, signifying the clinical and economic impact of $H$. pylori-related gastric diseases on the public health system (Sun et al. 2018). risk factors for acquisition of H. pylori infection (Malaty \& Graham 1994; Yucel et al. 2009). It is also believed that $H$. pylori infections mostly occur during early childhood in an intrafamilial transmission setting through both the fecal-oral and oral-oral routes as live bacterium had been previously successfully isolated from human fecal and oral sample (Awuku et al. 2017; Ertem 2013; Malaty et al. 2001; Parsonnet et al. 1999; Thomas et al. 1992; Urita et al. 2013; Yucel et al. 2009). Therefore, the best way of reducing $H$. pylori prevalence, perhaps, is to improve 
64 personal hygiene awareness among the primary caregivers of children, especially mothers, to

65 prevent childhood infection.

66

67 At present and overall, there is a lack of epidemiological investigation assessing the prevalence of H. pylori infection among the asymptomatic children in China. Therefore, this cross-sectional study aimed to examine $H$. pylori prevalence among healthy children from Kuichong Subdistrict situated in Shenzhen, China by using the ${ }^{13} \mathrm{C}$-urea breath test (UBT). The ${ }^{13} \mathrm{C}-\mathrm{UBT}$ was selected due to its non-invasive nature and has been proven to be highly accurate in determining $H$. pylori infection status in children aged 6 to 12 years (Elitsur et al. 2009). Plus, to allow more effective strategies to be drawn for the prevention and management of $H$. pylori infection in early childhood, we also explored the relations between $H$. pylori infection rate and different socioeconomic and demographic parameters to identify the potential risk factors.

77 Materials \& Methods

Ethics approval

The study was approved by the research ethics committee of the First Affiliated Hospital of

Shenzhen University, Shenzhen Second People's Hospital. Written and informed consents were obtained from all participants and their legal guardians. A blank copy of the human participant consent form is available as File S1. 


\section{Sample size determination}

85 According to a previous H. pylori prevalence study conducted in Guangzhou, we assumed that

$8622.9 \%$ of asymptomatic children would be infected with H. pylori (Chen et al. 2007). The

87 samples size required for this study was estimated based on a $95 \%$ confidence interval and a $2.5 \%$ admissible error rate using the following formula:

Sample size, $\mathrm{n}=\mathrm{Z}_{\alpha / 2}{ }^{2} \times \pi \times(1-\pi) / \delta^{2}$, where $\mathrm{Z}_{\alpha / 2}$ is the 2-tailed normal deviate for an $\alpha$ level of $0.05 ; \pi$ is the prevalence ratio; $\delta$ is the admission error rate.

A sample size of 1152 was therefore required for this study. We added at least $25 \%$ to the estimate for contingency purpose, raising the final sample size to 1355.

Study population

To avoid selection bias, from September 2018 to October 2018, all school children aged 6-12 years from four primary schools located in Kuichong Subdistrict of Shenzhen City, China, who did not meet any of the exclusion criteria and had provided parental or guardian consent, were recruited. Exclusion criteria included intake of antibiotics within the last four weeks, intake of proton pump inhibitors within the last two weeks and previous history of $H$. pylori eradication therapy.

The ${ }^{13} \mathrm{C}$-UBT (Beijing Boran Pharmaceutical, China) was performed according to the 
105

106

107

108

109

110

111

112

113

114

115

116

117

118

119

120

121

122

123

124

125

manufacturer's instructions to determine H. pylori infection status. All breath samples were

taken and analyzed immediately in the school by the same technician. Briefly, an initial baseline

breath was collected from each study participant following an overnight fast of at least four

hours. Each participant was then requested to ingest a tablet containing $75 \mathrm{mg}{ }^{13} \mathrm{C}$ labelled urea

with $80-100 \mathrm{~mL}$ of water. After 30 minutes of sitting, exhalation was again collected. The ${ }^{13} \mathrm{CO}_{2}$

content within the initial and 30-min expiratory air bags were analyzed using an HG-IRIS13C

infrared spectrometer (Beijing Richen-Force Science \& Technology Co., China). The

concentration of ${ }^{13} \mathrm{CO}_{2}$ following 30 minutes of administration that exceeded the baseline by $4 \%$

was regarded as a positive indicator of $H$. pylori infection. The weight, height, and both head and

chest circumferences of each participant were also recorded. Body mass index (BMI) was

calculated as body weight divided by height squared $\left(\mathrm{kg} / \mathrm{m}^{2}\right)$. The BMI category was classified

according to the corresponding percentiles as recommended by The Centers for Disease Control

and Prevention (CDC).

\section{Questionnaires}

On behalf of each study participant, parents or legal guardians were requested to complete a questionnaire for data collection on sociodemographic and living conditions, birth method and childhood feeding practices, lifestyle habits and health parameters. A blank copy of the questionnaire is available as File S2. The outcomes are summarized in supplementary file Table S1. Sociodemographic and living conditions consisted of age and gender of all children, number

of siblings ( 3 categories: 1, 2-3 and $>3$ ), total annual income ( 2 categories: $\leq 200,000$ or $>200,000$ 
126

127 128 129

RMB), household population ( 2 categories: $\leq 3$ or $>3$ persons), household space ( 2 categories: $\leq 40$ or $>40 \mathrm{~m}^{2} /$ person), parents' education level ( 2 categories: both were high school graduates or either one had completed tertiary education) and pet ownership (2 categories: yes or no).

The birth method of each child was assessed in 2 categories (via natural delivery or a caesarean section). Childhood feeding practices comprised the primary feeder of young children (4 categories: parents, grandparents, both parents and grandparents, or other caregivers), feeding methods ( 3 categories: feeding pre-chewed food, feeding by using shared cutleries or feeding by using a separate set of cutleries), breast feeding duration ( 3 categories: never, up to 6 months or more than 6 months) and how the milk bottle temperature was tested ( 3 categories: by dripping a few onto the wrist, taking a swig or using a thermometer).

7

Lifestyle investigations included the teeth brushing frequency ( 3 categories: $\leq 3,4-6$ or $\geq 7$ times per week), hand washing before meal and after toilet (3 categories: rarely, sometimes or always), dining out frequency ( 3 categories: $\leq 1,2-4$ or $\geq 5$ times per week), how fruit was eaten ( 2 categories: peeled or unpeeled), drinking water for consumption (2 categories: raw or boiled), toothbrush sharing ( 2 categories: yes or no), snacking regularly ( 2 categories: yes or no) and thumb sucking ( 2 categories: yes or no). The health conditions of each child were evaluated in 3 categories ( $\leq 1,2-4$ or $\geq 5$ times per week) for bloating, abdominal discomfort, burping and diarrhea, respectively, and in 2 categories (present or absent) for halitosis, anemia, asthma and skin allergy, respectively. 
148 Statistical analysis

149 Unpaired, two-tailed Student's $t$-test was used for statistical comparison of continuous variables between $H$. pylori positive and negative groups. For comparison of categorical variables, the chisquare test was employed, followed by univariate logistic regression analysis using JASP software v0.11.1 (https://jasp-stats.org/). Variables significantly associated with $H$. pylori infection in the univariate test $(P<0.05)$ were selected as candidates for entry into the multivariable logistic regression models using the forward selection process. During this iterative selection process, any variable with $P>0.1$ was eliminated. Subsequently, variables previously not included in the original model were introduced, one at a time, to identify any variable that could have an important role in H. pylori infection in the presence of significant variables retained earlier. The selection process was repeated but only for the additionally loaded variables until a final model was obtained. Both univariate and multivariate analyses were adjusted for age. Results were presented as odds ratio (OR) with 95\% confidence intervals (CI). A $p$-value of less than 0.05 was regarded as statistically significant.

\section{Results}

Prevalence of $H$. pylori infection

In this study, 1355 children aged from 6 to 12 years were recruited, among which 747 (55.1\%) were males and $608(44.9 \%)$ were females (Table 1$)$. The overall $H$. pylori prevalence rate was 
167 16.7\% (226/1355; 95\% CI: 14.7\%-18.7\%). There was no distinguishable difference in H. pylori

168 infection rate in gender and between children who were locally and elsewhere born.

169 Interestingly, while 8-year-old children had the highest prevalence of $H$. pylori infection at

$17023.2 \%$, lower than the overall prevalence positivity rates were seen in children aged 6 and 10

171 years old, at $10.6 \%$ and $12.6 \%$, respectively. No significant differences in anthropometric

172 measurements were observed among the infected and non-infected children.

174 We performed chi-square test to examine for any significant difference in different

175 sociodemographic, lifestyle and clinical characteristics between $H$. pylori-positive and H. pylori-

176 negative children. Variables tested with no significant difference between both groups are

177 available in supplementary file Table S2. As demonstrated in Table 2, the following variables contributed to greater $H$. pylori prevalence among children: having more than one child, both parents attended no education after high school, smaller living space, testing milk bottle temperature by taking a swig, feeding infant with pre-chewed food or by using feeder's cutlery, sharing toothbrush, eating out at least 5 times a week, snacking and eating fruits after peeling.

\section{Protective and risk factors for $\boldsymbol{H}$. pylori infection}

Risk factors for $H$. pylori infection were further investigated by univariate and multivariable

logistic regression analyses adjusting for age. The final model of multivariable analysis revealed

186 six variables significantly associated with $H$. pylori in children (Table 3 ). Children whose parent(s) with tertiary education level (OR: 0.64; 95\% CI: 0.46-0.89; $\mathrm{P}=0.008)$ and larger living 
188 189 190

space at home (OR: $0.54 ; 95 \%$ CI: $0.28-1.07 ; \mathrm{P}=0.078)$ were protective factors against $H$. pylori infection. Conversely, testing milk bottle temperature by taking a swig as opposed to dripping a few onto the wrist (OR: $1.79 ; 95 \% \mathrm{CI}: 1.19-2.68 ; P=0.005$ ), sharing of cutlery between the feeding person and young children rather than using separate cutlery each during meals (OR: 1.84; $95 \%$ CI: $1.22-2.78 ; P=0.004$ ), and snacking (OR: $1.43 ; 95 \%$ CI: $1.01-2.01 ; P=0.043$ ) resulted in lower risks for H. pylori infection. Only eating fruits peeled than unpeeled (OR: 2.56; 95\% CI: $1.4-4.71 ; P=0.002)$ and eating out frequently for at least 5 times a week (OR: 3.13 ; 95\% CI: 1.46-6.68; $P=0.003$ ) would result in substantially higher risks for $H$. pylori infection.

\section{Discussion}

In the present study, $H$. pylori infection in 1355 children aged 6-12 years was screened using the non-invasive ${ }^{13} \mathrm{C}-\mathrm{UBT}$, which has been shown to achieve both sensitivity and specificity of at least $95 \%$ in children and adults (Vaira \& Vakil 2001). The overall H. pylori prevalence was $16.7 \%$, which was at least two-fold higher compared to the global infection rate of $7.9 \%$ among children aged 7-12 years from Beijing, Guangzhou and Chengdu (Ding et al. 2015). In contrast to Beijing, Guangzhou and Chengdu which are all highly developed cities, Kuichong is only a developing subdistrict of the Shenzhen City. Therefore, the higher H. pylori infection rate among Kuichong's children is likely due to the differences in socioeconomic status and living conditions. Our data demonstrated that parent(s) with higher education level and having a larger living space at home are important protective factors against $\mathrm{H}$. pylori infection. These findings 
208

209

210

211

212

213

214 215

are consistent with several previous studies from Houston, Czech Republic, Iran and Vietnam that reported children living in a crowded household and whose parent(s) with less education are at significantly greater risks of acquiring $H$. pylori infection (Malaty et al. 2001; Nguyen et al. 2017; Nouraie et al. 2009; Sykora et al. 2009).

Poor hygiene practices when feeding the young ones such as giving pre-chewed food and the use of same spoon by both mother and child are among the risk factors of $H$. pylori infection in children (Nguyen et al. 2017; van Duynhoven \& de Jonge 2001). Our study demonstrated that testing milk bottle temperature by taking a few sucks directly and using the same cutlery to feed young children would result in a slight but significant increased risk of $H$. pylori infection. This implies that $H$. pylori exists in the human oral cavity and can be transmitted from an infected individual to another person via the oral-oral route (Yee 2017). Hence to reduce the infection risk in children, whoever is the primary carer at home for the young children should exercise good personal hygiene to avoid any food that is to be served to children being cross-contaminated by his/her saliva, especially one who knows him/herself is a $H$. pylori carrier.

In a previous investigation conducted in Peru, children were exposed to greater risk of $H$. pylori infection due to increased consumption of food from street vendors (Begue et al. 1998). Similarly, in the present study, frequent dining out was significantly associated with the acquisition of $H$. pylori infection in children., which could be attributed to the preparation of food by food handlers who did not practice good personal hygiene. 
230 While washing and peeling help to remove surface bacteria from fruits and vegetables to reduce

231 the risk of foodborne illness, intriguingly, eating peeled fruits would increase the risk of $H$.

232 pylori infection in this study. As our data showed that consumption of unboiled water is not

233 associated with $H$. pylori infection, we therefore ruled out our initial thought that the cause of

234 this increased risk might be due to contaminated water source. Unfortunately, we did not

235 question what the fruit was being consumed. Could it possibly be that the fruit peel contains anti-

236 H. pylori property and eating the fruit without its skin had therefore resulted in an elevated

237 infection risk? This warrants further investigation. Also, interestingly, children who seemed to

238 snack had a greater chance of acquiring H. pylori infection. Again, it was not specified further

239 within the questionnaire on what snacks were being consumed to allow us making a better

240 assumption on the underlying cause.

242 We concede that there are limitations in our study. Firstly, to assess the risk factors of H. pylori infection among children, a cohort study or a case-control study should be conducted, rather than

244 a cross-sectional study which is not the most appropriate option. However, it is important to mention that the basic findings of a cross-sectional study could serve as the foundation for preparing and designing further in-depth case-control studies, cohort studies or randomized controlled trial studies (Mann 2003). Another limitation lies within the questionnaire design as there were questions not explicit and detailed enough to examine the fundamental cause of some risk factors for $H$. pylori infection identified in this study, this warrants improvement before 
250 conducting a future cohort study to validate our current findings.

251

\section{Conclusions}

253 There is a high prevalence of $H$. pylori among children aged 6-12 years in Shenzhen City, China.

254 Larger living space at home and parent(s) with tertiary education level were protective factors

255 against $H$. pylori infection in children. Testing milk bottle temperature by taking a swig, not

256 using individual cutlery set when feeding young children and snacking were associated with

257 lower risks for $H$. pylori infection. Only eating fruits peeled than unpeeled and frequent dining

258 out for at least 5 times a week could lead to higher risks for H. pylori infection. 


\section{References}

260

261

262

263

264

265

266

267

268

269

270

271

272

273

274

275

276

277

278

279

280

281

282

283

284

285

286

287

288

289

290

291

292

293

294

295

296

297

Awuku YA, Simpong DL, Alhassan IK, Tuoyire DA, Afaa T, and Adu P. 2017. Prevalence of helicobacter pylori infection among children living in a rural setting in Sub-Saharan Africa. BMC Public Health 17:360. 10.1186/s12889017-4274-z

Begue RE, Gonzales JL, Correa-Gracian H, and Tang SC. 1998. Dietary risk factors associated with the transmission of Helicobacter pylori in Lima, Peru. Am J Trop Med Hyg 59:637-640. 10.4269/ajtmh.1998.59.637

Chen J, Bu XL, Wang QY, Hu PJ, and Chen MH. 2007. Decreasing seroprevalence of Helicobacter pylori infection during 1993-2003 in Guangzhou, southern China. Helicobacter 12:164-169. 10.1111/j.15235378.2007.00487.x

Ding Z, Zhao S, Gong S, Li Z, Mao M, Xu X, and Zhou L. 2015. Prevalence and risk factors of Helicobacter pylori infection in asymptomatic Chinese children: a prospective, cross-sectional, population-based study. Aliment Pharmacol Ther 42:1019-1026. 10.1111/apt.13364

Elitsur Y, Tolia V, Gilger MA, Reeves-Garcia J, Schmidt-Sommerfeld E, Opekun AR, El-Zimaity H, Graham DY, and Enmei K. 2009. Urea breath test in children: the United States prospective, multicenter study. Helicobacter 14:134-140. 10.1111/j.1523-5378.2009.00670.x

Ertem D. 2013. Clinical practice: Helicobacter pylori infection in childhood. Eur J Pediatr 172:1427-1434. 10.1007/s00431-012-1823-4

Feng RM, Zong YN, Cao SM, and Xu RH. 2019. Current cancer situation in China: good or bad news from the 2018 Global Cancer Statistics? Cancer Commun (Lond) 39:22. 10.1186/s40880-019-0368-6

Hooi JKY, Lai WY, Ng WK, Suen MMY, Underwood FE, Tanyingoh D, Malfertheiner P, Graham DY, Wong VWS, Wu JCY, Chan FKL, Sung JJY, Kaplan GG, and Ng SC. 2017. Global Prevalence of Helicobacter pylori Infection: Systematic Review and Meta-Analysis. Gastroenterology 153:420-429. 10.1053/j.gastro.2017.04.022

Malaty HM, and Graham DY. 1994. Importance of childhood socioeconomic status on the current prevalence of Helicobacter pylori infection. Gut 35:742-745. 10.1136/gut.35.6.742

Malaty HM, Logan ND, Graham DY, and Ramchatesingh JE. 2001. Helicobacter pylori infection in preschool and school-aged minority children: effect of socioeconomic indicators and breast-feeding practices. Clin Infect Dis 32:1387-1392. 10.1086/320148

Mann CJ. 2003. Observational research methods. Research design II: cohort, cross sectional, and case-control studies. Emerg Med J 20:54-60. 10.1136/emj.20.1.54

Marshall BJ, and Windsor HM. 2005. The relation of Helicobacter pylori to gastric adenocarcinoma and lymphoma: pathophysiology, epidemiology, screening, clinical presentation, treatment, and prevention. Med Clin North Am 89:313-344, viii. 10.1016/j.mcna.2004.09.001

Nguyen TVH, Phan TTB, Nguyen VB, Hoang TTH, Le TLA, Nguyen TTM, and Vu SN. 2017. Prevalence and Risk Factors of Helicobacter pylori Infection in Muong Children in Vietnam. Ann Clin Lab Res 5. 10.21767/23865180.1000159

Nouraie M, Latifi-Navid S, Rezvan H, Radmard AR, Maghsudlu M, Zaer-Rezaii H, Amini S, Siavoshi F, and Malekzadeh R. 2009. Childhood hygienic practice and family education status determine the prevalence of Helicobacter pylori infection in Iran. Helicobacter 14:40-46. 10.1111/j.1523-5378.2009.00657.x

Parsonnet J, Shmuely H, and Haggerty T. 1999. Fecal and oral shedding of Helicobacter pylori from healthy infected

Peer] reviewing PDF | (2019:11:42914:2:0:NEW 3 Mar 2020) 
adults. JAMA 282:2240-2245. 10.1001/jama.282.23.2240

Sun XJ, Shi JF, Guo LW, Huang HY, Yao NL, Gong JY, Sun YW, Liu GX, Mao AY, Liao XZ, Bai YN, Ren JS, Zhu XY, Zhou JY, Mai L, Song BB, Liu YQ, Zhu L, Du LB, Zhou Q, Xing XJ, Lou PA, Sun XH, Qi X, Wang Y, Cao R, Ren Y, Lan L, Zhang K, He J, Wang JL, Dai M, and listed authors are on behalf of the Health Economic Evaluation Working Group CSPiUC. 2018. Medical expenses of urban Chinese patients with stomach cancer during 2002-2011: a hospital-based multicenter retrospective study. BMC Cancer 18:435. 10.1186/s12885-018-4357-y

Sykora J, Siala K, Varvarovska J, Pazdiora P, Pomahacova R, and Huml M. 2009. Epidemiology of Helicobacter pylori infection in asymptomatic children: a prospective population-based study from the Czech Republic. Application of a monoclonal-based antigen-in-stool enzyme immunoassay. Helicobacter 14:286-297. 10.1111/j.1523-5378.2009.00689.x

Thomas JE, Gibson GR, Darboe MK, Dale A, and Weaver LT. 1992. Isolation of Helicobacter pylori from human faeces. Lancet 340:1194-1195. 10.1016/0140-6736(92)92894-I

Urita Y, Watanabe T, Kawagoe N, Takemoto I, Tanaka H, Kijima S, Kido H, Maeda T, Sugasawa Y, Miyazaki T, Honda Y, Nakanishi K, Shimada N, Nakajima H, Sugimoto M, and Urita C. 2013. Role of infected grandmothers in transmission of Helicobacter pylori to children in a Japanese rural town. J Paediatr Child Health 49:394-398. 10.1111/jpc.12191

Vaira D, and Vakil N. 2001. Blood, urine, stool, breath, money, and Helicobacter pylori. Gut 48:287-289. 10.1136/gut.48.3.287

van Duynhoven YT, and de Jonge R. 2001. Transmission of Helicobacter pylori: a role for food? Bull World Health Organ 79:455-460.

Yee JKC. 2017. Are the view of Helicobacter pylori colonized in the oral cavity an illusion? Exp Mol Med 49 :e397. 10.1038/emm.2017.225

Yucel O, Sayan A, and Yildiz M. 2009. The factors associated with asymptomatic carriage of Helicobacter pylori in children and their mothers living in three socio-economic settings. Jpn J Infect Dis 62:120-124. 


\section{Table $\mathbf{1}$ (on next page)}

Demographic characteristics and anthropometric measurements of 1355 children recruited in this study.

Note: Data are presented as $\mathrm{n}(\%)$ or mean \pm standard deviation. BMI: body mass index. 
1 Table 1. Demographic characteristics and anthropometric measurements of 1355 children

2 recruited in this study.

\begin{tabular}{|c|c|c|c|}
\hline & H. pylori positive & H. pylori negative & $P$ \\
\hline Age (years) & & & 0.032 \\
\hline $6(n=160)$ & $10.6(5.7-15.5)$ & $89.4(84.5-94.3)$ & \\
\hline $7(n=231)$ & $16.5(11.6-21.4)$ & $83.5(78.6-88.4)$ & \\
\hline $8(n=207)$ & $23.2(17.3-29.1)$ & $76.8(70.9-82.7)$ & \\
\hline $9(n=260)$ & $18.1(13.3-22.9)$ & $81.9(77.1-86.7)$ & \\
\hline $10(n=223)$ & $12.6(8.2-17)$ & $87.4(83-91.8)$ & \\
\hline $11(n=202)$ & $17.8(12.4-23.2)$ & $82.2(76.8-87.6)$ & \\
\hline $12(n=72)$ & $16.7(7.9-25.5)$ & $83.3(74.5-92.1)$ & \\
\hline Gender & & & 0.704 \\
\hline Male $(n=747)$ & $16.3(13.6-19)$ & $83.7(81-86.4)$ & \\
\hline Female $(n=608)$ & $17.1(14-20.2)$ & $82.9(79.8-86)$ & \\
\hline \multicolumn{4}{|l|}{ Birthplace } \\
\hline Dapeng & $15.7(13-18.4)$ & $84.3(81.6-87)$ & 0.265 \\
\hline Others & $17.9(14.8-21)$ & $82.1(79-85.2)$ & \\
\hline BMI & & & 0.404 \\
\hline Underweight & $16.5(10.2-22.8)$ & $83.5(77.2-89.8)$ & \\
\hline Normal & $15.8(13.4-18.2)$ & $84.2(81.8-86.6)$ & \\
\hline Overweight & $18.8(12.5-25.1)$ & $81.2(74.9-87.5)$ & \\
\hline Obese & $21.8(13.6-30)$ & $78.2(70-86.4)$ & \\
\hline Height (cm) & $134.2 \pm 11.8$ & $134.5 \pm 11.9$ & 0.76 \\
\hline Weight (kg) & $30.6 \pm 9.6$ & $30.2 \pm 8.9$ & 0.596 \\
\hline Head circumference (cm) & $52.5 \pm 1.7$ & $52.6 \pm 2.2$ & 0.381 \\
\hline Chest circumference (cm) & $65.8 \pm 36.8$ & $63.5 \pm 20.5$ & 0.369 \\
\hline
\end{tabular}

3 Note: Data are presented as \% (95\% confidence interval) or mean \pm standard deviation. BMI:

4 body mass index. The age, gender, birthplace and BMI differences between $H$. pylori-positive

5 and negative children were compared using the chi-square test. For differences involving

6 continuous parameters including height, weight, head circumference and chest circumference,

7 the comparison was performed using the unpaired Student's $t$-test. 


\section{Table 2 (on next page)}

List of sociodemographic, lifestyle and clinical variables that had significant influence on H. pylori infection status in 1355 children. 
1 Table 2. List of sociodemographic, lifestyle and clinical variables that had significant influence

2 on $H$. pylori infection status in 1355 children.

\begin{tabular}{|c|c|c|c|}
\hline Variables & $\begin{array}{l}\text { H. pylori } \\
\text { positive }\end{array}$ & $\begin{array}{l}\text { H. pylori } \\
\text { negative }\end{array}$ & $p$ \\
\hline Number of children & & & 0.027 \\
\hline $1(n=341)$ & $12.6(9-16.2)$ & $87.4(83.8-91)$ & \\
\hline 2 or $3(n=918)$ & $17.5(15-20)$ & $82.5(80-85)$ & \\
\hline$>3(n=96)$ & $22.9(14.3-31.5)$ & $77.1(68.5-85.7)$ & \\
\hline Parents education level & & & 0.001 \\
\hline Both were high school graduates $(n=843)$ & $19.2(16.5-21.9)$ & $80.8(78.1-83.5)$ & \\
\hline $\begin{array}{r}\text { Either one or both had completed tertiary } \\
\text { education }(n=512)\end{array}$ & $12.5(9.6-15.4)$ & $87.5(84.6-90.4)$ & \\
\hline Living space (m2/person) & & & 0.037 \\
\hline$\leq 40(n=1249)$ & $17.3(15.2-19.4)$ & $82.7(80.6-84.8)$ & \\
\hline$>40(n=106)$ & $9.4(3.7-15.1)$ & $90.6(84.9-96.3)$ & \\
\hline $\begin{array}{l}\text { How to test the temperature of milk bottle } \\
\text { before feeding? }\end{array}$ & & & $<0.001$ \\
\hline Wrist method $(n=1149)$ & $15.1(13-17.2)$ & $84.9(82.8-87)$ & \\
\hline Mouth testing $(n=164)$ & $27.4(20.4-34.4)$ & $72.6(65.6-79.6)$ & \\
\hline Thermometer $(n=42)$ & $16.7(5.2-28.2)$ & $83.3(71.8-94.8)$ & \\
\hline Infant feeding method & & & 0.002 \\
\hline Pre-mastication $(n=43)$ & $25.6(12.3-38.9)$ & $74.4(61.1-87.7)$ & \\
\hline Sharing cutlery with the feeder $(n=158)$ & $24.7(17.8-31.6)$ & $75.3(68.4-82.2)$ & \\
\hline Using child-only cutlery $(n=1150)$ & $15(12.9-17.1)$ & $85(82.9-87.1)$ & \\
\hline Fruits were peeled before eating & & & 0.036 \\
\hline No $(n=143)$ & $10.5(5.4-15.6)$ & $89.5(84.4-94.6)$ & \\
\hline Yes $(n=1212)$ & $17.4(15.2-19.6)$ & $82.6(80.4-84.8)$ & \\
\hline Sharing toothbrush & & & 0.014 \\
\hline No $(n=1218)$ & $15.8(13.7-17.9)$ & $84.2(82.1-86.3)$ & \\
\hline Yes $(n=137)$ & $24.1(16.8-31.4)$ & $75.9(68.6-83.2)$ & \\
\hline Frequency of eating out & & & 0.002 \\
\hline$\leq 1$ time per week $(n=1074)$ & $15.8(13.6-18)$ & $84.2(82-86.4)$ & \\
\hline $2-4$ times per week $(n=248)$ & $17.3(12.5-22.1)$ & $82.7(77.9-87.5)$ & \\
\hline$\geq 5$ times per week $(n=33)$ & $39.4(22.4-56.4)$ & $60.6(43.6-77.6)$ & \\
\hline Snacking habit & & & 0.032 \\
\hline No $(n=398)$ & $13.3(9.9-16.7)$ & $86.7(83.3-90.1)$ & \\
\hline Yes $(n=957)$ & $18.1(15.6-20.6)$ & $81.9(79.4-84.4)$ & \\
\hline
\end{tabular}

3 Note: Data are presented as \% (95\% confidence interval). The differences between $H$. pylori-

4 positive and negative children were compared using the chi-square test. 


\section{Table 3(on next page)}

Univariate and multivariable logistic regression analyses of variables associated with $H$. pylori infection status.

Note: OR, odds ratio; $\mathrm{Cl}$, confidence interval. 
1 Table 3. Univariate and multivariable logistic regression analyses of variables associated with $H$.

2 pylori infection status.

\begin{tabular}{|c|c|c|c|c|}
\hline \multirow{2}{*}{ Variables } & \multicolumn{2}{|c|}{ Univariate } & \multicolumn{2}{|c|}{ Multivariable } \\
\hline & OR (95\% Cl) & $\boldsymbol{P}$ & OR (95\% Cl) & $\boldsymbol{P}$ \\
\hline \multicolumn{5}{|l|}{ Number of children } \\
\hline - & Reference & & & \\
\hline 2-3 & $1.44(1-2.07)$ & 0.05 & & \\
\hline$>3$ & $2.06(1.16-3.66)$ & 0.013 & & \\
\hline \multicolumn{5}{|l|}{ Parents education level } \\
\hline $\begin{array}{r}\text { Both were high school } \\
\text { graduates }\end{array}$ & Reference & & Reference & \\
\hline $\begin{array}{r}\text { Either one or both had } \\
\text { completed tertiary } \\
\text { education }\end{array}$ & $0.59(0.43-0.81)$ & 0.001 & $0.64(0.46-0.89)$ & 0.008 \\
\hline \multicolumn{5}{|l|}{ Living space (m²/person) } \\
\hline$\leq 40$ & Reference & & Reference & \\
\hline$>40$ & $0.51(0.26-0.99)$ & 0.047 & $0.54(0.28-1.07)$ & 0.078 \\
\hline \multicolumn{5}{|l|}{$\begin{array}{l}\text { Milk bottle temperature test } \\
\text { method }\end{array}$} \\
\hline Wrist method & Reference & & Reference & \\
\hline Mouth testing & $2.05(1.39-3.01)$ & $<0.001$ & $1.79(1.19-2.68)$ & 0.005 \\
\hline Thermometer & $1.13(0.5-2.59)$ & 0.766 & $1.06(0.45-2.46)$ & 0.899 \\
\hline \multicolumn{5}{|l|}{ Infant feeding method } \\
\hline Using child-only cutlery & Reference & & Reference & \\
\hline Pre-mastication & $1.96(0.97-3.95)$ & 0.062 & $1.69(0.81-3.54)$ & 0.163 \\
\hline Using feeder's cutlery & $1.86(1.25-2.77)$ & 0.002 & $1.84(1.22-2.78)$ & 0.004 \\
\hline \multicolumn{5}{|l|}{ Frequency of eating out } \\
\hline$\leq 1$ time per week & Reference & & Reference & \\
\hline 2-4 times per week & $1.1(0.76-1.6)$ & 0.606 & $1.2(0.82-1.77)$ & 0.347 \\
\hline$\geq 5$ times per week & $3.23(1.55-6.73)$ & 0.002 & $3.13(1.46-6.68)$ & 0.003 \\
\hline \multicolumn{5}{|l|}{$\begin{array}{l}\text { Fruits were peeled before } \\
\text { eating }\end{array}$} \\
\hline No & Reference & & Reference & \\
\hline Yes & $2.06(1.14-3.71)$ & 0.017 & $2.56(1.4-4.71)$ & 0.002 \\
\hline \multicolumn{5}{|l|}{ Sharing toothbrush } \\
\hline No & Reference & & & \\
\hline Yes & $1.6(1.04-2.46)$ & 0.032 & & \\
\hline \multicolumn{5}{|l|}{ Snacking habit } \\
\hline No & Reference & & Reference & \\
\hline Yes & $1.44(1.03-2.01)$ & 0.034 & $1.43(1.01-2.01)$ & 0.043 \\
\hline
\end{tabular}

3 Note: OR, odds ratio; CI, confidence interval. Both univariate and multivariable logistic

4 regression analyses were performed to identify risk factors associated with $H$. pylori infection. 